\title{
O MODO DE CONHECIMENTO DO GÊNIO E DO SANTO
}

\author{
THE MODE OF KNOWLEDGE OF THE GENIUS AND THE SAINT
}

RESUMO: O gênio e o santo são figuras de destaque na filosofia de Schopenhauer, pois a elas é atribuída a capacidade de conhecer de um modo privilegiado, adquirida através de uma modificação na forma como os seres humanos usualmente conhecem. Essa forma de conhecimento se caracteriza por sua independência em relação ao princípio de razão suficiente, que acontece quando o intelecto se liberta do domínio da vontade. A liberdade intelectual pode proporcionar tanto a contemplação estética para o gênio quanto o quietivo da vontade para o santo. O nosso objetivo será mostrar que o quietivo possui um aspecto que o diferencia da contemplação, visto que somente ele caracteriza a negação da vontade de viver, pois esta, ao interromper a afirmação da vontade, promove simultaneamente a destruição do corpo, o qual é considerado o foco a partir do qual a vontade se afirma.

PALAVRAS-CHAVE: Contemplação estética. Negação da vontade de viver. Gênio. Santo. Schopenhauer.

ABSTRACT: Genius and saint are prominent figures in Schopenhauer's philosophy because they have the ability to know in a privileged way - an ability acquired through a modification in the way human beings usually know. This form of knowledge is characterized by its independence from the Principle of Sufficient Reason, which happens when the intellect is freed from the domain of the will. Intellectual freedom can provide both the aesthetic contemplation to the genius and the quieter of the will to the saint. We aim to show that the quieter of the will has an aspect that differentiates it from contemplation. Only the quieter of will characterizes the denial of the will to live, for, by interrupting the assertion of the will, this denial simultaneously promotes the destruction of the body, which is considered the focus from which the will is affirmed.

KEYWORDS: Aesthetic contemplation. Denial of the will to live. Genius. Saint. Schopenhauer.

O gênio e o santo são figuras extremamente importantes na filosofia de Schopenhauer, porque a elas é atribuída a capacidade de conhecer de um modo privilegiado. Para compreender o modo específico como eles conhecem, é preciso primeiramente considerar o significado do conceito schopenhaueriano de objetidade da vontade, o qual consiste na "vontade que se tornou objeto, isto é, que se tornou representação" (SCHOPENHAUER, WWV I, \30, p. 199 / MVR I, 2005, p. 235). ${ }^{2}$ A objetidade "tem muitos e bem específicos graus, nos quais a essência da Vontade aparece gradualmente na representação com crescente nitidez

\footnotetext{
${ }^{1}$ Doutora em Filosofia pela Universidade de São Paulo (USP) e Membro da Seção Brasileira da Schopenhauer-Gesellschaft.

${ }^{2}$ As referências às citações extraídas das obras de Schopenhauer contêm primeiramente as abreviaturas adotadas pela Schopenhauer-Gesellschaft em seu periódico Schopenhauer-Jahrbuch e, a seguir, aquelas das traduções utilizadas.
} 
e completude" (SCHOPENHAUER, WWV I, \30, p. 199 / MVR I, 2005, p. 235). Schopenhauer considera que o grau mais nítido e completo de objetidade corresponde àquilo que Platão denominou Ideias, "na medida em que são justamente espécies determinadas, ou formas e propriedades originárias e imutáveis dos corpos orgânicos e inorgânicos, bem como das forças naturais que se manifestam segundo leis da natureza" (WWV I, 』 30, p. 199 / MVR I, 2005, p. 235).

A Ideia caracteriza um modo superior e extraordinário de conhecimento porque com ela se conhece os modelos de onde provêm os múltiplos indivíduos e fenômenos particulares. Esses modelos representam a unidade ou a matriz a partir da qual se manifestam as inúmeras cópias que se tornam acessíveis ao conhecimento de um indivíduo. Essas cópias, como coisas particulares, são apenas objetidades mediatas da Vontade, ou seja, são objetos conhecidos por intermédio das formas subordinadas do princípio de razão. Estas formas são o espaço, o tempo e a causalidade, as quais não se aplicam ao conhecimento da Ideia, o que a isenta de mudanças e pluralidade, tornando-a "imutável, única, a mesma" (SCHOPENHAUER, WWV I, \30, p. 200 / MVR I, 2005, p. 236), e faz com que ela seja considerada a única objetidade imediata da Vontade. A imediatez no conhecimento da Ideia também pode ser explicada pelo fato de ela estar situada entre as coisas particulares e a Vontade, na medida em que a Ideia

simplesmente se despiu das formas subordinadas do fenômeno concebidas sob o princípio de razão; ou antes, ainda não entrou em tais formas. Porém, a forma primeira e mais universal ela conservou, a da representação em geral, a de ser-objeto para um sujeito. (SCHOPENHAUER, WWV I, 『32, p. 206 / MVR I, 2005, p. 242).

Ao ser colocada nessa posição intermediária, a Ideia se distingue tanto daquilo que é individual quanto da Vontade considerada como essência ou coisa em si mesma. O objetivo será mostrar que tanto o gênio quanto o santo são capazes de conhecer a Ideia; porém o santo é aquele que, ao conhecer a Ideia, conhece simultaneamente a essência da vontade como coisa em si mesma. Primeiramente será tratado como o gênio conhece a Ideia e, a seguir, como o santo conhece a essência da Vontade.

Para a compreensão do modo como o artista alcança a genialidade, transformando-se em puro sujeito do conhecimento, é preciso considerar que, "caso as Ideias devam se tornar objeto de conhecimento, isso só pode ocorrer pela supressão da individualidade no sujeito cognoscente" (SCHOPENHAUER, WWV I, $\$ 30$, p. 200 / MVR I, 2005, p. 236). Pois o sujeito, considerado como um indivíduo, só pode conhecer a multiplicidade que resulta da submissão das Ideias às formas subordinadas do fenômeno concebidas sob o princípio de razão. Portanto, o gênio é aquele que, na medida em que se torna capaz de conhecer a Ideia, suprime a própria individualidade e, ao mesmo tempo, liberta o seu intelecto do domínio da vontade, visto que a supressão da individualidade e a liberdade do intelecto são eventos interdependentes. A questão é saber como essa forma de conhecimento 
se torna possível, a partir de uma modificação na forma como os seres humanos usualmente conhecem.

Schopenhauer sustenta que o conhecimento, tanto nos animais quanto no ser humano, é uma função do intelecto, considerado um órgão derivado da vontade e, portanto, secundário em relação a ela. Conhecer é a forma de apresentar à vontade determinados objetos que possam satisfazê-la em cada circunstância. Essa forma de conhecimento é aquela regida pelas formas subordinadas do princípio de razão. São essas formas que permitem a percepção de um objeto particular, situado em meio à diversidade de outros objetos, com os quais ele mantém relações que dão origem aos questionamentos sobre o onde, o quando, o porquê e o para quê das coisas. São os objetos assim apreendidos que permitem ao intelecto perceber o mundo como uma multiplicidade capaz de fornecer os motivos de satisfação da vontade, o que torna o intelecto um órgão destinado a trabalhar em favor da vontade, a fim de satisfazê-la:

Pelo modo como se determina, o intelecto é apenas o meio dos motivos: por isso, originalmente, não apreende das coisas nada além de suas relações com a vontade, as diretas, as indiretas ou as meramente possíveis. No caso dos animais, em que ele permanece quase inteiramente nas relações diretas, o assunto fica mais evidente justamente por causa disto. Aquilo que não faz referência à própria vontade não existe para eles. [...] No caso de uma pessoa normal, as relações indiretas e, de fato, as relações possíveis com a vontade são adicionadas, e a soma delas constitui o conjunto dos conhecimentos úteis, mas mesmo aqui o conhecimento permanece confinado às relações. Portanto, uma imagem totalmente pura e objetiva das coisas não é alcançada pela cabeça normal, porque a sua força de intuição [Anschauungskraft] logo se torna cansada e inativa, tão logo não seja estimulada e posta em movimento pela vontade. (SCHOPENHAUER, WWV II, Kap. 31, pp. 428-9 / MVR II, 2014, pp. 31-2)

A libertação do intelecto da sua determinação original acontece devido a uma mudança na forma como ele usualmente conhece, que lhe permite conhecer não um objeto particular, mas a sua Ideia:

Quando [...] abandonamos o modo comum de consideração das coisas, cessando de seguir apenas suas relações mútuas conforme o princípio de razão, cujo fim último é sempre a relação com a própria vontade; [...] Quando, por assim dizer, o objeto é separado de toda relação com algo exterior a ele e o sujeito da sua relação com a vontade, o que é conhecido não é mais a coisa particular enquanto tal, mas a Idéia, a forma eterna, a objetidade imediata da vontade neste grau. Por aí, o sujeito cessa de ser meramente individual e, agora, é puro sujeito do conhecimento destituído de Vontade, sem mais seguir as relações conforme o princípio de razão, mas concebe em fixa contemplação o objeto que lhe é oferecido, exterior à conexão com outros objetos, repousando e absorvendo-se nessa contemplação. (SCHOPENHAUER, WWV I, 』 34, p. 210 / MVR I, 2005, p. 246). 
Para Schopenhauer, o conhecimento da Ideia, a introdução da Ideia na nossa consciência, exige de nós, como condição prévia, uma mudança que pode ser considerada um "ato de autoabnegação" [Akt der Selbstverleugnung] (SCHOPENHAUER, WWV II, Kap. 30, p. 417 / MVR II, 2015, p. 439). Pois esse conhecimento depende da supressão da subjetividade, somente através da qual pode surgir a objetidade perfeita. Essa mudança se caracteriza pela separação completa entre o conhecimento obtido pelo intelecto e a vontade. Para que ocorra esta separação, o intelecto deve considerar as coisas como se elas não tivessem qualquer relação com a vontade, pois este é o único meio para o conhecimento se tornar o puro reflexo da natureza objetiva das coisas. A modificação assim exigida no sujeito, que consiste em eliminar de si todo querer, não pode derivar da vontade, motivo pelo qual essa modificação não pode ser um ato do arbítrio, sendo por isto considerada um evento súbito, inesperado, imprevisível e, como será mostrado, instável.

Schopenhauer esclarece que nossa consciência tem duas faces: de uma parte ela é o conhecimento de nós mesmos, quer dizer, da nossa própria vontade; e de outra parte ela é o conhecimento intuitivo do mundo exterior, apercepção dos objetos. Quando se conhece a Ideia, um dos lados da consciência emerge totalmente, enquanto o outro se apaga. Por causa disto, quanto mais perfeitamente nos tornarmos conscientes de uma coisa, menor é a consciência do nosso próprio eu, até que o conhecimento intuitivo ocupe totalmente a nossa consciência. (Cf. SCHOPENHAUER, WWV II, Kap. 30, pp. 417-8 / MVR II, 2014, p. 20). O predomínio completo do conhecimento intuitivo na consciência é o que qualifica a perfeita objetidade, para a qual é necessária a liberdade do intelecto.

$\mathrm{Na}$ filosofia de Schopenhauer, o intelecto é considerado um órgão derivado da vontade e, portanto, secundário em relação a ela; sua função original é atuar a favor da vontade, atendendo aos seus interesses. A libertação do intelecto ocorre com o auxílio da razão, que está situada abaixo do intelecto na hierarquia que atribui à vontade a importância máxima, pois todas as funções cognitivas se originam da vontade. A função da razão é formar conceitos por meio de abstrações, as quais são formadas a partir das intuições empíricas fornecidas pelo intelecto. A atividade da razão é, portanto, dependente do intelecto, o que a posiciona como um órgão terciário em relação à vontade.

Apesar da sua condição inferior nessa hierarquia, a razão possui um papel decisivo na libertação do intelecto do domínio da vontade. Para compreender esse aspecto da atividade racional, é preciso considerar inicialmente que a diferença entre os seres humanos e os irracionais está em que a vontade humana não é satisfeita ou motivada apenas por objetos que são percebidos diretamente pelo intelecto; pois a abstração atua no conhecimento do ser humano e permite que ele também seja motivado por lembranças do passado, por antecipações futuras, e, até mesmo, por eventos imaginados, o que torna a satisfação da vontade humana um processo mais complexo do que aquele atribuído aos seres irracionais. A capacidade de abstração permite que o homem leve em conta outros motivos além daqueles que ele percebe imediatamente, visto que a deliberação que precede a sua ação inclui pensamentos e conceitos. A ação de refletir, também proveniente 
da razão, amplia o conhecimento abstrato, ao permitir que o homem estabeleça relações não apenas entre os motivos constituídos pelos objetos intuídos e a vontade, mas também entre os pensamentos e os conceitos obtidos por abstração, o que distancia cada vez mais o conhecimento do intelecto da sua relação com a vontade e favorece o conhecimento da Ideia.

Segundo Schopenhauer, a função do intelecto humano é conhecer as relações entre as coisas e a vontade ou, então, tendo em vista a complementação deste conhecimento, as relações das coisas umas com as outras. ${ }^{3}$ A chave para a compreensão do modo como acontece o conhecimento da Ideia e, simultaneamente, a libertação do intelecto, é o fato de que a "apreensão das relações das coisas umas com as outras ocorre apenas indiretamente a serviço da vontade" (SCHOPENHAUER, WWV II, Kap. 29, p. 414 / MVR II, 2014, p. 13). Por isto, tal apreensão, por não proporcionar a satisfação direta da vontade, favorece a transição do conhecimento subjetivo para o conhecimento puramente objetivo. Assim, por um lado, o conhecimento objetivo - que revela o ser em si ou a natureza essencial de um objeto - é totalmente diferente das relações que constituem o modo como o objeto é conhecido no processo de satisfação da vontade; mas, por outro lado, o conhecimento dessa natureza essencial pode ser construído gradualmente a partir de meras relações, se estas forem múltiplas, variadas e imediatamente apreendidas, pois, através deste modo de apreensão, "a servidão [Dienstbarkeit] do intelecto em relação à vontade se torna, ao mesmo tempo, mais e mais indireta e limitada" (SCHOPENHAUER, WWV II, Kap. 29, p. 414 / MVR II, 2014, p. 14). Consequentemente, quanto mais o intelecto apreender imediatamente as relações entre as coisas, ou seja, quanto mais estas relações não servirem diretamente de motivos para a vontade, maior será o conhecimento objetivo de um fenômeno. O exemplo abaixo ilustra este modo de apreensão objetiva:

\begin{abstract}
Pode ser que, ao subir uma montanha, surja a ideia de permanecer no topo atuando como motivo e, como contramotivo, a ideia do perigo da queda; ambos os motivos permanecem em referência imediata à minha vontade. Eu posso então também me perguntar se o belo sentimento que eu ligo à visão do topo estaria relacionado com o fato de eu ter vencido o perigo. Essa reflexão ainda permanece em relação com a minha vontade, mas de modo apenas mediato. Por fim, posso chegar possivelmente a me perguntar, de modo bem geral e sem qualquer relação com aquilo que quero ou não quero, se toda felicidade resulta de um perigo vencido e nada mais é que a mera negação do sofrimento. No exemplo fica claro como o pensar, em consequência do discernimento [Besonnenheit], se desliga cada vez mais das relações com a vontade e se torna objetivo. (KOßLER, 2015, p. 26).
\end{abstract}

A construção da Ideia de felicidade como negação do sofrimento tem início com o conflito entre dois motivos que atuam imediatamente sobre a vontade: o prazer de permanecer no topo da montanha ou o desprazer relacionado ao medo

\footnotetext{
${ }^{3}$ As relações das coisas entre si é um tipo de conhecimento que "aparece com algum volume e significado apenas no intelecto humano; no caso dos animais, por outro lado, existe apenas de modo limitado, mesmo quando o seu intelecto já é consideravelmente desenvolvido" (SCHOPENHAUER, WWV II, Kap. 29, p. 414 / MVR II, 2014, p. 13/ WWV II, 414).
} 
da queda; porém, somente a reflexão que proporciona o estabelecimento de relações que se vinculam apenas indiretamente com essas intuições promovem o distanciamento progressivo dos sentimentos que fazem uma referência direta à vontade e, assim, pode levar à apreensão de uma Ideia de felicidade dotada de objetividade.

A razão tem, portanto, dois modos de atuar no conhecimento: por um lado, ela auxilia o intelecto a satisfazer a vontade, fornecendo a ela motivos constituídos por abstrações que, entretanto, só podem ser obtidas a partir das intuições do intelecto; e, por outro lado, a razão permite que o intelecto se desligue progressivamente do conhecimento destinado à satisfação vontade, através do aumento de objetividade proporcionado ao conhecimento, cujo ápice é a apreensão da essência objetiva ou da Ideia de uma coisa.

Essa objetividade não deve ser confundida com o conceito de objeto que, na teoria do conhecimento de Schopenhauer, é definido como objetivação da intuição empírica, quando o entendimento constrói, para uma dada sensação, a sua causa no tempo e no espaço, tornando a intuição algo que se coloca externamente diante do sujeito (Cf. KOßLER, 2015, p. 26). Essa intuição é definida por Schopenhauer como uma objetidade inadequada, pois ela não diz respeito ao próprio objeto, mas ao objeto como meio de satisfação da vontade e, portanto, ela não é objetiva no sentido da independência da vontade. A objetidade adequada, por sua vez, corresponde ao conceito schopenhaueriano de Ideia, que também pode ser entendido como "o resultado da soma de todas as relações" que constituem "o caráter peculiar da coisa" (SCHOPENHAUER, WWV II, Kap. 29, p. 414 / MVR II, 2014, p. 14) e que proporciona a apreensão da natureza essencial de um objeto. A apreensão desta natureza, por depender das relações obtidas por meio da reflexão, exige o uso mais elevado da capacidade racional e permite o tipo de conhecimento no qual o intelecto atua livre do domínio da vontade, caracterizando a forma de conhecer que é própria ao gênio artístico:

Ver o universal no particular é sempre precisamente a característica fundamental do gênio, enquanto o homem normal reconhece de modo específico apenas as coisas particulares, pois a efetividade só lhe interessa no que faz referência à sua própria vontade [...]. De acordo com isto, o verdadeiro objeto do gênio é apenas a natureza essencial das coisas em geral, o universal em si, a totalidade. (SCHOPENHAUER, WWV II, Kap. 31, p. 432 / MVR II, 2014, p. 35-36).

O conhecimento da natureza essencial de uma coisa exige que o gênio ultrapasse os limites da intuição comum por meio da clareza de consciência [Besonnenheit] decorrente de um alto grau de reflexão. Essa clareza é necessária não só para o conhecimento do gênio, mas também para o do santo, visto que ambos podem alcançar a objetidade perfeita, através de um modo de conhecimento que é independente da relação com a vontade. Entretanto, se a clareza de consciência é uma característica comum a ambos, o modo de alcançála é específico para cada um, pois o gênio a alcança por meio da intuição do caráter de um objeto, enquanto o santo a alcança mediante a intuição do caráter 
da sua própria vontade, pois o conhecimento do santo consiste na intuição de um objeto que pertence especificamente ao autoconhecimento. ${ }^{4}$

A intuição do caráter de uma coisa - seja de um objeto exterior, seja da própria vontade - equivale à intuição da sua natureza essencial, considerada como a unidade da qual provêm as suas manifestações empíricas, na medida em que esta unidade exige a supressão da individualidade daquele que a intui. Porém, a intuição do gênio ainda não o leva ao conhecimento da essência da coisa em si mesma, visto que esta é concebida não apenas como a unidade da qual provém a totalidade das representações de um objeto, mas como a unidade da qual provém a totalidade do mundo da representação.

Ao intuir o caráter da sua própria vontade através do autoconhecimento, o santo se configura como um caso específico, pois o seu acesso ao conhecimento objetivo também exige, assim como no caso do gênio, a supressão da sua individualidade; porém esta supressão, diferentemente do que acontece para o gênio, proporciona-lhe não apenas a intuição do caráter ou da essência da sua própria vontade, mas também, de modo simultâneo, a intuição da essência da vontade como coisa-em-si mesma.

A exposição mais detalhada da diferença entre o conhecimento do santo e o do gênio exige o esclarecimento da distinção estabelecida por Schopenhauer entre a Ideia e a coisa-em-si mesma:

Uma Ideia [...] não corresponde ainda à própria essência da coisa em si, pela simples razão de que se originou a partir do conhecimento de meras relações. No entanto, como resultado da soma de todas as relações, [a Ideia] é o caráter peculiar da coisa e, portanto, a expressão completa do ser que se exibe à intuição como objeto, apreendido não em relação a um indivíduo, mas como ele se expressa espontaneamente e, desta forma, determina todas as suas relações, as únicas que eram conhecidas até então. (SCHOPENHAUER, WWV II, Kap. 29, p. 414 / MVR II, 2014, p. 14).

A Ideia também se diferencia da intuição comum, pois, nesta, apenas um lado do objeto é apreendido, ou seja, aquele que interessa à vontade. A transição possível do conhecimento comum das coisas particulares para o conhecimento das Ideias só acontece quando todos os outros lados do objeto são apreendidos, o que acontece no gênio por meio da fantasia. Segundo Schopenhauer, "o gênio precisa da fantasia para ver nas coisas não o que a natureza efetivamente formou, mas o que se esforçava por formar, mas que, devido à luta de suas formas entre si, não pôde levar a um bom termo" (WWV I, 』 36, p. 220 / MVR I, 2005, p. 255). Através da fantasia, o gênio pode ampliar o seu conhecimento para além dos limites possibilitados pela intuição comum, visto que "os objetos efetivos são quase sempre apenas exemplares bastante imperfeitos da Idéia que neles se expõe"

${ }^{4}$ A clareza de consciência também é comum ao filósofo, visto que ele, assim, como o santo, é capaz de conhecer a essência das coisas. Porém o filósofo conclui a essência das coisas enquanto o santo a intui. Para obter a conclusão sobre a essência do mundo, considerando-a como a unidade da qual os fenômenos são a manifestação empírica, o filósofo relaciona pensamentos e conceitos e conecta a experiência externa com a interna. 
(SCHOPENHAUER, WWV I, 』36, p. 220 / MVR I, 2005, p. 255). A fantasia também permite que a intuição artística ultrapasse a realidade da experiência pessoal do artista, visto que essa intuição não está limitada às Ideias dos objetos que ele percebe diretamente:

Os objetos do gênio, enquanto tais são as Ideias, as formas essenciais e permanentes do mundo e de todos os seus fenômenos. O conhecimento da Idéia, todavia, é necessariamente intuitivo, não abstrato. Em consequência, o conhecimento do gênio seria limitado às Ideias dos objetos efetivamente presentes à sua pessoa, e seria portanto dependente da concatenação das circunstâncias que conduz a eles, se a fantasia não ampliasse o seu horizonte, alargando-o para além da realidade de sua experiência pessoal. Portanto, a fantasia põe o gênio na condição de, a partir do pouco que chegou à sua apercepção efetiva, construir todo o resto e assim desfilar diante de si quase todas as imagens possíveis da vida. (SCHOPENHAUER, WWV I, 』36, pp. 219-20 / MVR I, 2005, p. 255).

Diferentemente do poder da fantasia para o gênio, o elemento que permite ao santo ampliar os limites da sua experiência pessoal é o sofrimento, visto que, assim como acontece para o gênio, o conhecimento da Ideia pelo santo também ocorre pela via intuitiva. Porém seu conhecimento não pode estar restrito à intuição comum, ou seja, ao modo como ele pessoalmente sente e, consequentemente, sofre. Por isto o santo precisa, além de vivenciar diretamente o sofrimento de forma intensa e persistente, aceitá-lo como uma espécie de cura para o mal representado pela força insaciável da vontade de viver.

$\mathrm{Na}$ afirmação, quando o intelecto atua para satisfazer a vontade, o sofrimento representa aquilo que deve ser evitado ou suprimido. Para que o sofrimento deixe de atuar a favor da afirmação e passe a contribuir com a negação, é necessário compreender que o sofrimento não é apenas aquilo que nos afeta pessoalmente ou aquilo que afeta o outro e que pode ser conhecido intuitivamente através da compaixão, mas, sobretudo, como aquilo que caracteriza a essência da vontade. Além disto, é necessário compreender que o sofrimento constitui o elemento que, ao enfraquecer a vontade de viver, possibilita o acesso e a permanência na negação da vontade.

O poder do santo de intuir o sofrimento como sendo a essência da vontade se origina da capacidade que todo ser humano tem de conhecer a sua própria vontade. Esse tipo de autoconhecimento acontece em decorrência do corpo ser o foco de manifestação da vontade de viver de cada indivíduo. Essa manifestação acontece no corpo de dois modos: internamente, através daquilo que cada um sente como bem-estar e mal-estar e, externamente, através das ações, as quais podem ser conhecidas não só pelo próprio sujeito, mas também pelos outros.

No processo de autoconhecimento, a relação entre os próprios sentimentos e as ações é de identidade. Isto significa que aquilo que cada um sente como prazer ou desprazer não pode ser considerado como a causa das ações corporais, pois, para Schopenhauer, as ações do corpo são apenas a expressão empírica desses sentimentos e estes, por sua vez, são a manifestação mais imediata da 
própria vontade. Essa imediatez se caracteriza pelo fato dos sentimentos se manifestarem independentemente do espaço. Porém, eles ainda permanecem submetidos ao tempo e preservam a forma própria do conhecimento enquanto tal, ou seja, a divisão entre sujeito e objeto, visto que os sentimentos são objetos de conhecimento que são acessíveis somente àquele que os sente. Considerando que a pluralidade de ações praticadas por um indivíduo - as quais dizem respeito ao seu caráter empírico - remetem ao único ato de vontade que evidencia o seu caráter inteligível, o autoconhecimento contém a particularidade de permitir o conhecimento dos sentimentos que constituem o elo de ligação entre o caráter empírico e o caráter inteligível.

O conhecimento do caráter inteligível equivale ao conhecimento da Ideia de um indivíduo ou da essência da sua própria vontade. Porém, como o conhecimento da Ideia pressupõe a supressão da individualidade, o conhecimento da essência da própria vontade é o único caso em que o puro sujeito do conhecimento, ao conhecer a Ideia, conhece não apenas o caráter que revela a sua natureza essencial, mas a essência da vontade como coisa-em-si, ou seja, da vontade como a unidade metafísica de todas as manifestações empíricas que constituem o mundo da representação. Resta esclarecer alguns outros aspectos da passagem do conhecimento dos sentimentos para o conhecimento do caráter inteligível ou da Ideia que corresponde a esse caráter e, então, da Ideia para a essência da vontade como coisa-em-si.

Para compreender essas transições é necessário considerar que o sofrimento é necessário para percorrer os caminhos que conduzem os caracteres morais em direção à negação da vontade, pois ele corresponde aos sentimentos de desprazer ou de dor. Estes sentimentos são o modo mais imediato da manifestação da vontade em nós, visto que, para Schopenhauer, o prazer só pode ser compreendido como a supressão do desprazer. Quando sentimos dor ou conhecemos diretamente a dor do outro através da compaixão, nós podemos adquirir a consciência daquilo que Schopenhauer considera a força primordial do agir. Tudo o que acontece na natureza tem uma causa e, por outro lado, é a causa de um efeito; o intelecto que atua a serviço da vontade pode conhecer e esclarecer causas e efeitos, mas ele não pode conhecer a força que dá origem à sequência causal. Somente o agir humano pertence a uma espécie de causalidade que permite o conhecimento da sua força originária, ou seja, da vontade como coisa-em-si. O conhecimento dessa força exige que se considere, por um lado, que cada ação corporal é a manifestação do resultado do conflito entre os motivos que remetem aos sentimentos de prazer ou de dor que nos afetam em cada circunstância; e, por outro lado, que cada uma de nossas ações é a manifestação externa de um ato da nossa vontade, cuja manifestação interna acontece através dos nossos sentimentos.

A dor ou o desprazer que dão origem ao sofrimento, por nos afetarem diretamente, são sentimentos fundamentais, visto que o prazer que almejamos só pode ser alcançado através da supressão do desprazer e da dor. Além disto, o sofrimento está intimamente relacionado à satisfação da vontade, pois, para que essa satisfação aconteça, temos que evitar os motivos que nos fazem sofrer. Assim, quanto maior for o conhecimento sobre as coisas e as circunstâncias que nos 
causam dor ou desprazer, maior será o conhecimento sobre a nossa própria vontade. Porém, por melhor que seja esta forma de autoconhecimento, ela não pode, por si só, levar-nos ao conhecimento da essência da nossa vontade, pois este conhecimento só pode ser alcançado quando o intelecto se torna capaz de conhecer o sofrimento objetivamente, ou seja, de forma desinteressada, e não com a finalidade de evitá-lo.

O conhecimento objetivo decorrente do autoconhecimento é possibilitado pelo modo específico como o ser humano conhece os motivos de satisfação da sua vontade, porque os motivos abstratos, proporcionados pela razão, são a principal motivação humana. Através da abstração, é possível, por exemplo, prever quais são os objetos capazes de nos fazer sofrer, tendo por base o nosso sofrimento anterior; também é possível almejarmos o prazer através de objetos que ainda não foram efetivamente usufruídos. Isto acontece porque a razão permite que o intelecto estabeleça relações entre a vontade e os objetos constituídos por pensamentos e conceitos. Como estes objetos não são imediatamente intuídos, eles se caracterizam como motivos que se relacionam apenas indiretamente com a vontade.

É a predominância das relações indiretas entre os motivos e a vontade que favorece a transição do conhecimento destinado à satisfação da vontade para o conhecimento objetivo. Porém, tanto para o gênio quanto para o santo, o conhecimento da Ideia não acontece como consequência do simples aumento da quantidade de relações indiretas, visto que, mesmo que a razão forneça ao intelecto um grande número dessas relações, o conhecimento ainda pode permanecer a serviço da vontade. O que caracteriza a objetividade do conhecimento é a libertação do intelecto, e esta libertação, por não ser um ato proveniente do arbítrio, só pode ocorrer espontaneamente.

No caso do santo, a explicação sobre o modo como o seu intelecto se liberta do domínio da vontade precisa levar em conta que os sentimentos, por constituírem o elo de ligação entre as ações e a vontade, surgem na autoconsciência de um modo fragmentado. Para compreender como acontece essa fragmentação, é preciso primeiramente considerar que os sentimentos são objetos que não se situam no espaço; porém, a forma do tempo, assim como a diferença entre o ser em si do objeto e a percepção deste ser em si no sujeito que o conhece permanecem no conhecimento dos sentimentos. Assim, conhecer a própria vontade equivale a conhecer os nossos sentimentos de modo consecutivo, ou seja, em uma sequência temporal. Por causa disto, nós conhecemos a nossa vontade apenas em seus atos isolados e sucessivos, não em seu todo, tal como ela é em si e por si.

Também o fato de que nós só podemos conhecer imediatamente a nossa vontade enquanto ela é sentida como prazer ou dor decorre da percepção segundo a forma do tempo. Por causa disto, "eu sei diretamente o que é a dor apenas durante o tempo em que eu a sinto" (KOßLER, 2000, p. 95). Assim, se a dor que eu sinto desaparecer, eu só poderei me referir a ela indiretamente, ou seja, do mesmo modo que uma pessoa que me viu sofrendo. Esse modo de conhecimento indireto também pode contribuir com a fuga da dor que caracteriza a afirmação da 
vontade, pois o conhecimento daquilo que me fez sofrer no passado pode ser utilizado para evitar que eu sofra novamente pelos mesmos motivos. Se na filosofia de Schopenhauer o sofrimento é considerado como inerente à vida, a capacidade de abstração decorrente da razão permite que o ser humano viva do modo menos infeliz possível.

O que precisa ser enfatizado é que o modo de conhecimento da Ideia alcançado pelo santo não contribui com a fuga da dor que caracteriza a afirmação da vontade; pois, para o santo, o sofrimento deixa de ser um motivo e se torna quietivo da vontade. Isto acontece em decorrência do santo ser capaz de eliminar as formas do princípio de razão que ainda subsistem na sua percepção do sentimento de dor, o que o torna capaz de sentir a dor que manifesta diretamente a essência da vontade. Essas formas subsistentes, como já foi dito, são o tempo e a divisão entre sujeito e objeto. Ao suprimir estas formas, o santo intui a Ideia de sofrimento, que, por sua vez, equivale à intuição da essência da vontade. Porém, o que o santo nega não é apenas a essência da sua própria vontade, que ele compreende como necessariamente sofredora e cuja Ideia equivale ao seu caráter inteligível. Pois o pressuposto para que ele possa conhecê-la é a supressão da sua própria individualidade. Assim, ao conhecer intuitivamente a essência da sua própria vontade, o santo conhece simultaneamente a essência da vontade que se manifesta empiricamente em todos os indivíduos.

O problema é que a supressão de todas as formas do princípio de razão, a exemplo do que acontece também para o gênio, não depende do arbítrio do sujeito que conhece, exatamente porque essa supressão pressupõe a separação entre o intelecto e a vontade e caracteriza a liberdade intelectual. Por causa disto, temos sempre que considerar o conhecimento da Ideia como um evento súbito, inesperado e inexplicável. Quem, portanto, suprime espontaneamente essas formas na percepção do sentimento de dor, torna-se um puro sujeito do conhecimento, podendo, a partir daí e também de modo espontâneo, ou afirmar conscientemente a vontade ou negá-la. O santo é aquele que ultrapassa o limite da afirmação, negando a vontade.

A negação da vontade é um evento metafísico que modifica o modo como a vontade se manifesta empiricamente. Se, na afirmação da vontade, as ações de um indivíduo correspondem ao modo como o seu caráter inteligível se manifesta empiricamente, o agir baseado nas práticas ascéticas passa a ser o modo de manifestação da supressão desse caráter, ou seja, da negação da vontade. Além disso, a explicação do ascetismo como sendo o modo de manifestação da negação da vontade inclui o fato de que a continuidade das práticas ascéticas tende a destruir o corpo, considerado o foco de manifestação da afirmação da vontade e aquilo que caracteriza empiricamente a individualidade do sujeito.

A negação - que em si mesma é um evento metafísico e, por isto, pressupõe um conhecimento independente das formas do princípio de razão - continua a se manifestar empiricamente, sob as formas desse princípio, enquanto o corpo permanecer vivo. Por causa disto, Schopenhauer admite considerar o quietivo como uma espécie de motivo e, enquanto tal, ele também pode ser considerado uma expressão da lei da causalidade. O quietivo seria o motivo que leva 
necessariamente o santo às práticas ascéticas, cuja finalidade é destruir o seu corpo que, enquanto manifestação empírica da vontade, é um objeto situado no espaço. Por isto, na negação, o corpo do santo ainda permanece como a expressão empírica de uma individualidade que, metafisicamente, já deixou de existir. Tudo acontece a partir da consideração de dois planos: no metafísico, a supressão da individualidade acontece de um só golpe; porém, no plano empírico, a manifestação dessa supressão só pode ocorrer segundo as formas do princípio de razão, razão pela qual a destruição do corpo acontece pouco a pouco, segundo a forma do tempo, por meio das práticas ascéticas motivadas pelo quietivo.

Como a destruição do corpo ocorre paulatinamente, Schopenhauer prevê a possibilidade de uma reversão no modo de conhecimento alcançado pelo santo, antes que a morte do seu corpo se concretize; consequentemente, a vontade ainda pode, mesmo após o início da negação, voltar a afirmar-se. Isto é possível porque a prática do ascetismo, que flagela o corpo, é o modo de manifestar e preservar a negação; mas a vida que continua a animar o corpo do santo, mesmo debilitado em consequência dessa prática, permanece como um foco residual de afirmação da vontade. Por causa disto, a vida daqueles que iniciaram a negação é permeada por uma luta constante, a fim de impedir o regresso à afirmação:

[...] não se deve imaginar que, desde a negação da Vontade de vida ter entrado em cena pelo conhecimento tornado quietivo, não haja oscilação, e assim se possa para sempre permanecer nela como numa propriedade herdada. Não, antes a negação precisa ser renovadamente conquistada por novas lutas. Pois, visto que o corpo é a Vontade mesma apenas na forma da objetidade ou como fenômeno do mundo como representação, segue-se que toda Vontade de vida existe segundo sua possibilidade enquanto o corpo viver, sempre esforçando-se para aparecer na realidade efetiva e de novo arder em sua plena intensidade. Por isso ao encontrarmos na vida de homens santos aquela calma e bemaventurança que descrevemos apenas como a florescência nascida da constante ultrapassagem da Vontade, vemos também como o solo onde se dá essa floração é exatamente a contínua luta com a Vontade de Vida: pois sobre a face da terra ninguém pode ter paz duradoura. Em consequência, observemos as histórias de vida interior dos santos cheias de conflitos espirituais, tentações e abandono da graça, isto é, daquele modo de conhecimento que, ao tornar todos os motivos ineficientes, emudece, como quietivo universal, qualquer querer e proporciona a mais profunda paz e abre o portão da liberdade. Consequentemente, também vemos os que uma vez atingiram a negação da Vontade de vida se manterem com todo empenho neste caminho através de todo tipo de renúncias auto-impostas, mediante um modo de vida duro, penitente e procura do desagradável: tudo tendo em vista suprimir a Vontade que renovadamente se esforça. Ao fim, como já conhecem o valor da redenção, cuidam angustiosamente para conservar a salvação alcançada [...]. - Sob o termo, por mim já amiúde empregado, de ascese, entendo no seu sentido mais estrito essa quebra proposital da Vontade pela recusa do agradável e a procura do desagradável, mediante o modo de vida penitente voluntariamente escolhido e a autocastidade, tendo em vista a mortificação contínua da vontade. Tudo isso pode ser observado na prática das pessoas que já atingiram a negação da Vontade e 
tentam mantê-la. (SCHOPENHAUER, WWV I, \ 68, p. 462-3 / MVR I, 2005, p. 496).

Mesmo considerando que a negação se manifesta pela mortificação da vontade, é preciso observar que essa mortificação, que ocorre através das práticas ascéticas, não é o que efetivamente impede o retorno à afirmação; pois essa forma de comportamento é apenas uma espécie de sintoma indicativo de que o modo de conhecimento que caracteriza a negação ainda prevalece sobre aquele que caracteriza a afirmação. A origem da instabilidade atribuída à negação da vontade é uma decorrência da espontaneidade responsável pelo surgimento ou desaparecimento do conhecimento independente do princípio de razão, o que impede que o santo, apesar de todos os seus esforços, tenha um efetivo controle sobre a manifestação da negação que nele acontece.

A instabilidade inerente ao modo de conhecimento alcançado pelo santo também acontece para o gênio, pois o acesso que este tem ao conhecimento da Ideia, o qual lhe proporciona a contemplação estética, também não é passível de um controle. Mesmo sendo um modo de conhecimento almejado pelo gênio, a contemplação surge de um modo súbito e desaparece da mesma forma, o que transforma a genialidade em um estado impossível de ser vivenciado permanentemente. Para o santo, o modo de conhecimento que possibilita a negação ocasiona a destruição progressiva do seu corpo e, caso essa destruição persista, provocará a sua morte, impedindo-o de retornar ao estado de afirmação. Isto diferencia a santidade da genialidade, pois, mesmo que o gênio vivencie acessos repetidos ao conhecimento da Ideia, isto não afetará a integridade do seu corpo, considerado o foco de manifestação da sua vontade e a marca da sua individualidade empírica.

Além disso, o gênio se caracteriza por uma forte individualidade quando não se encontra no estado de contemplação. A força da sua individualidade resulta do afastamento progressivo entre o seu intelecto e a sua vontade, o qual é necessário para que ele possa manifestar a genialidade em alguns momentos. Por outro lado, é justamente a supressão da sua individualidade que caracteriza os seus estados de contemplação e criação artísticas, os quais duram apenas o suficiente para a concepção e produção de suas obras. Por isto, o artista apresenta um comportamento inconstante, decorrente da alternância entre a vivência de uma individualidade vigorosa e a supressão desta individualidade. A instabilidade no comportamento do gênio aparece porque

[...] ora ele é egocêntrico, hipersensível e descontrolado pelas menores coisas e $\log$ se torna novamente soberano sobre o cotidiano, trabalha concentrado e de modo infinitamente paciente em sua obra ou então está tranquilamente imerso na contemplação. Essa alternância de estados acontece porque, durante o processo criativo, é como se a personalidade genial viesse de fora e invadisse o artista, arrancando-o de sua vida até então inconstante e o conduzisse à criação [...]. Schopenhauer não apenas constata essa súbita transformação, mas a deriva do discernimento [Besonnenheit] que, quando está presente em grande medida, pode ter duas consequências contrapostas. Se 
permanece a referência dos pensamentos e representações à vontade, então o discernimento conduz a uma vontade marcadamente individual; mas justamente nesse estado pode ocorrer facilmente que a referência à vontade, graças ao grande número de coisas presentes e relações, seja "esquecida". (KOßLER, 2015, p. 29).

Um outro aspecto importante que deve ser considerado quando se trata da objetividade acessível ao gênio e ao santo envolve a questão do interesse, pois a Ideia deve ser considerada uma forma de conhecimento desinteressado, ou seja, um conhecimento no qual o intelecto atua independentemente dos interesses provenientes da satisfação da vontade. Porém, seria possível atribuir ao gênio, mas não ao santo, uma espécie de interesse puramente intelectual.

Para explicar o tipo de interesse presente na atividade artística, podemos considerar que o sofrimento, enquanto objeto de conhecimento, é acessível tanto ao gênio quanto ao santo, e que ambos podem conhecê-lo objetivamente, ou seja, como Ideia. Porém o santo é aquele que conhece objetivamente o sofrimento pela via interna, por meio dos seus próprios sentimentos de desprazer e de dor, ou por meio da intuição imediata do sofrimento do outro, ou seja, através da compaixão. Já o gênio conhece objetivamente o sofrimento pela via externa, através do sofrimento que ele percebe indiretamente em um outro indivíduo ou no mundo, e que, portanto, não é sentido por ele pessoalmente. Entretanto, enquanto indivíduo, o gênio, excetuando os seus momentos de contemplação, também sofre. Além disso, como o gênio conhece o sofrimento como algo diferente dele mesmo, a intuição desse objeto, quando se dá de modo objetivo, leva-o a esquecer o sofrimento que ele próprio sente, o que torna os momentos em que ocorre essa intuição uma espécie de alívio para o sofrimento inerente à vida, transformando o acesso ao conhecimento da Ideia em um fim para o artista:

A fruição do belo, o consolo proporcionado pela arte, o entusiasmo do artista que o faz esquecer a penúria da vida, essa vantagem do gênio em face de todos os outros homens, única que o compensa pelo sofrimento que cresce na proporção de sua clareza de consciência [Klarheit des Bewußtseyns] e pela erma solidão em meio a uma multidão humana tão heterogênea - tudo isso se deve, como veremos adiante, ao fato de que o em-si da vida, a Vontade, a existência mesma é um sofrimento contínuo, em parte lamentável, em parte terrível; o qual, todavia, se intuído pura e exclusivamente como representação, ou repetido pela arte, apresenta-nos um teatro pleno de significados. Esse lado do mundo conhecido de maneira pura, bem como a repetição dele em alguma arte, é o elemento do artista. Ele é cativado pela consideração do teatro da objetivação da vontade. Detém-se nele, sem se cansar de considerá-lo e expô-lo repetidas vezes. Entrementes, ele mesmo arca os custos de encenação desse teatro, noutras palavras, ele mesmo é a Vontade que se objetiva a si mesma e permanece em contínuo sofrimento. Aquele conhecimento profundo, puro e verdadeiro da essência do mundo se torna um fim para o artista, que se detém nele. (SCHOPENHAUER, WWV I, $₫ 52$, pp. 315-6 / MVR I, 2005, p. 349350). 
A existência desse fim relacionado à contemplação da Ideia leva o artista a querer obtê-lo, visto que a contemplação se configura como um tipo de consolo em um mundo permeado pelo sofrimento. Mas a atribuição de uma finalidade à contemplação a coloca em contradição com a concepção de Ideia considerada como um conhecimento desinteressado, visto que a Ideia não pode ser um objeto de satisfação para a vontade, justamente porque sua apreensão depende da interrupção do domínio da vontade sobre o intelecto. A solução para essa dificuldade pode estar em uma distinção entre o prazer que pode ser proporcionado à vontade - através dos objetos que o intelecto lhe oferece e que serve para a sua satisfação - e o prazer puramente intelectual, que é obtido pelo gênio durante o conhecimento da Ideia e que não tem qualquer relação com a vontade. O prazer intelectual seria aquele decorrente do simples ato de conhecer ou do conhecimento considerado como um fim em si mesmo.

Ao admitirmos a existência de um prazer de origem intelectual, temos que considerar que o intelecto é um órgão derivado da vontade e, portanto, o prazer obtido através dele, mesmo após a sua separação da vontade, ainda seria uma forma, mesmo que indireta, de afirmar a vontade. A aceitação da existência desse tipo de afirmação nos impede de tratar a contemplação da Ideia como algum grau de negação, assim como nos permite diferenciar a contemplação acessível ao gênio da negação alcançada pelo santo. Esta diferenciação é confirmada por Schopenhauer quando ele afirma:

Eis por que o conhecimento profundo, puro e verdadeiro da essência do mundo não se torna para o gênio um quietivo da Vontade, não o salva para sempre da vida, mas apenas momentaneamente, contrariamente ao santo que atinge a resignação. Ainda não se trata, para o artista, da saída da vida, mas apenas de um consolo ocasional em meio a ela; até que sua força, aí incrementada, finalmente cansada do jogo, volte-se para o sério.

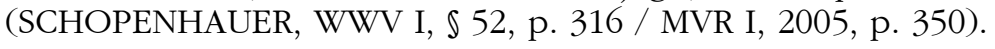

O consolo proporcionado ao gênio através do conhecimento da Ideia é apenas ocasional e temporário, visto que o gênio não tem um controle sobre essa forma de intuição. Schopenhauer se refere à interrupção no conhecimento da Ideia, que faz o gênio retornar à forma comum de conhecer, como o fim de um encanto:

Assim que surge novamente na consciência uma relação com a vontade, com a nossa pessoa, precisamente dos objetos intuídos puramente, o encanto chega ao fim. Recaímos no conhecimento regido pelo princípio de razão. Não mais conhecemos a Idéia, mas a coisa isolada, elo de uma cadeia à qual nós mesmos pertencemos. De novo estamos abandonados às nossas penúrias. (SCHOPENHAUER, WWV I, $₫ 38$, p. 233 / MVR I, 2005, p. 269).

Mas se o conhecimento da Ideia proporciona ao gênio um consolo que impede momentaneamente que ele sinta os sofrimentos inerentes à sua vida, o mesmo não acontece com o santo. Pois, ao suprimir a sua individualidade e as formas do princípio de razão na sua forma de conhecer, o santo esquece de si, inclusive dos objetos e das circunstâncias que o fazem particularmente sofrer; 
porém este esquecimento não o livra do sofrimento, mas, ao contrário, intensificao ao máximo, já que o santo deixa de sentir o seu próprio sofrimento para sentir aquele que afeta o mundo inteiro. Por causa disto, se o conhecimento objetivo produz no gênio um estado de felicidade plena, este mesmo tipo de conhecimento produz no santo um estado absoluto de mal-estar e sofrimento, que deve ser aceito resignadamente. A questão da resignação é importante para a compreensão do modo como o santo conhece a Ideia, visto que o desejo de não querer sofrer pode ser considerado como o sinal do retorno do domínio da vontade sobre o seu intelecto e, consequentemente, da reversão da negação em afirmação.

O conhecimento da Ideia de sofrimento, quando ocupa totalmente as funções do intelecto do santo, atua como um quietivo para a sua vontade, que não só impede a vontade de continuar a se afirmar, mas também contribui para a destruição do seu corpo, considerado o foco residual de afirmação da sua vontade. Esse quietivo não pode ser considerado, ao contrário do prazer de origem intelectual sentido pelo gênio, como um meio indireto de satisfação da vontade, pois Schopenhauer considera que o quietivo é o único motivo capaz de negar a vontade. Porém, para que ele possa atuar como tal, o quietivo precisa ter força suficiente para vencer o ímpeto da vontade em busca de satisfação. Na afirmação, o conflito entre os motivos determina qual deles possui força suficiente para proporcionar a satisfação da vontade; na negação, o quietivo deve ter força suficiente para vencer a força de oposição proveniente da autopreservação, visto que esta força constitui o último reduto da afirmação da vontade, que subsiste, durante a negação, enquanto o santo viver.

\section{CONSIDERAÇÕES FINAIS}

A exposição do modo como o gênio e o santo conhecem a Ideia permitiu mostrar o que há em comum entre eles, mas também apontar as diferenças fundamentais entre a contemplação e a negação. A principal delas consiste no fato de que a contemplação estética realizada pelo gênio não deve ser considerada como um grau, mesmo que atenuado, de negação da vontade. Pois a negação se caracteriza pela oposição ao modo de afirmação, que se manifesta apenas através do ascetismo. Este tipo de comportamento, quando é persistente, resulta na destruição do corpo do santo, considerado o foco a partir do qual a sua vontade se afirma. O artista, por sua vez, ao manifestar a sua genialidade, apenas interrompe o domínio da vontade sobre o intelecto, proporcionando um acesso ao conhecimento da Ideia que, diferentemente do conhecimento da Ideia alcançado pelo santo, não prejudica a integridade do seu corpo. Por constituir um prazer desinteressado proveniente do intelecto, e sendo o intelecto um órgão secundário em relação à vontade, a contemplação estética seria um modo indireto de afirmar a vontade ou, pelo menos, ela não prejudicaria a continuidade da afirmação. Aquilo que qualifica a negação e que não está presente na atividade contemplativa é o movimento da vontade contra si mesma, que não só a aquieta, mas destrói o objeto empírico através do qual a vontade se afirma. 


\section{REFERÊNCIAS BIBLIOGRÁFICAS}

KOßLER, Matthias. Sobre o papel do discernimento [Besonnenheit] na estética de Arthur Schopenhauer. In: DEBONA, Vilmar et al. (Org.). Dogmatismo \& Antidogmatismo: filosofia crítica, vontade e liberdade. Uma homenagem a Maria Lúcia Mello Oliveira Cacciola. Tradução de Flamarion Caldeira Ramos. Curitiba: Editora UFPR, 2015.

SCHOPENHAUER, Arthur. O mundo como vontade e como representação, tomo I (MVR I). Tradução de Jair Barboza. São Paulo: Editora UNESP, 2005.

. O mundo como vontade e representação, tomo II, volume 2 (MVR II). Tradução de Eduardo Ribeiro da Fonseca. Curitiba: Editora UFPR, 2014.

O mundo como vontade e como representação, tomo II (MVR II). Tradução de Jair Barboza. São Paulo: Editora UNESP, 2015.

Recebido em: 01-08-2018

Aceito para publicação em: 02-11-18 